\title{
CROPS AND SOILS RESEARCH PAPER Applying the generalized additive main effects and multiplicative interaction model to analysis of maize genotypes resistant to grey leaf spot
}

\author{
C. R. L. ACORSI ${ }^{1}$, T. A. GUEDES ${ }^{1}$, M. M. D. COAN ${ }^{2 *}$, R. J. B. PINTO' ${ }^{2}$, C. A. SCAPIM ${ }^{2}$, \\ C. A. P. PACHECO ${ }^{3}$, P. E. O. GUIMARÃES ${ }^{3}$ AND C. R. CASELA ${ }^{3}$ \\ ${ }^{1}$ Departamento de Estatística (DES), Universidade Estadual de Maringá (UEM), Av. Colombo, 5.790 - Zip Code \\ 87020-900 Jd. Universitário, Maringá - Paraná, Brazil \\ ${ }^{2}$ Departamento de Agronomia (DAG), Universidade Estadual de Maringá (UEM), Av. Colombo, 5·790 - Zip Code \\ 87020-900 Jd. Universitário, Maringá - Paraná, Brazil \\ ${ }^{3}$ Embrapa Milho e Sorgo, CNPMS, Rodovia MG 424 km 45, CP 285 - Zip Code 35701-970 - Sete Lagoas, MG, Brazil
}

(Received 27 May 2014; accepted 22 November 2016)

\section{SUMMARY}

Analysing the stability and adaptation of cultivars to different environments is always necessary before recommending them for planting on large areas. Additive main effects and multiplicative interaction (AMMI) models have been used to analyse genotype-by-environment interactions $(\mathrm{G} \times \mathrm{E})$. AMMI models require data with homogeneous variance, normal errors and additive effects. However, agronomic data do not always conform to these statistical assumptions. The objective of the present study was to analyse $\mathrm{G} \times \mathrm{E}$ interactions for severity and incidence of grey leaf spot, a foliar disease in maize caused by Cercospora zeae-maydis, using a generalized AMMI model. Data were collected and evaluated for 36 maize cultivars from experiments carried out in nine Brazilian regions in 2010/11 by the Empresa Brasileira de Pesquisa Agropecuária (EMBRAPA - Milho e Sorgo). Only two of three stable genotypes defined by a quasi-likelihood model with a logistic link function could be recommended for their desirable agronomic characteristics. Four growing locations in which the genotypes were stable were identified, but in only one of these was stability associated with very severe grey leaf spot disease. Cultivars adapted to specific locations with low percentage disease severity were also identified.

\section{INTRODUCTION}

Optimal maize production depends on genotype (G), environment (E) and both together when there is significant $G \times E$ interaction (Allard 1999). Efforts have been made to quantify, minimize or make use of the $\mathrm{G} \times \mathrm{E}$ interaction when making strategic decisions regarding maize breeding (Cruz et al. 2006).

The additive main effects and multiplicative interaction (AMMI) models developed by Kempton (1984); Gauch \& Zobel (1988); Zobel et al. (1988) and Crossa et al. (1991) are important statistical methods for plant breeding. Although these models provide easy and simple methods for interpreting

\footnotetext{
* To whom all correspondence should be addressed. Email: marloncoan@gmail.com
}

parametric estimators, they require normally distributed data.

Kempton (1984) discusses the method of principal components (PC) as a way to summarize the response of a genotype to different environments. In this method, the matrix of estimated $\mathrm{G} \times \mathrm{E}$ interaction effects from the classical analysis of variance (ANOVA) model is subjected to principal component analysis (PCA). The $\mathrm{G} \times \mathrm{E}$ interaction is thus decomposed into a number of multiplicative terms. The hypothesis is that most of the $\mathrm{G} \times \mathrm{E}$ interaction can be explained by the first few terms of the PCA and that these have some meaningful interpretations.

The AMMI model has been applied since the 1990s to evaluate $\mathrm{G} \times \mathrm{E}$ interactions and allow breeders to recommend stable cultivars adapted to 
either broad or specific environments. However, the AMMI model can only be applied when the response variable $Y$ follows a normal distribution with a homogeneous variance. If these assumptions are not met, a methodology based on a generalized linear model (GLM) is more appropriate. Algorithms for generalized additive main effects and multiplicative interaction (GAMMI) developed by van Eeuwijk (1995) and Gabriel (1998) are based on the basic concepts for AMMI expanded by the theories of GLM and the quasi-likelihood method. These GAMMI models assume that the response variables have an exponential probability distribution. Earlier, Wedderburn (1974) established the quasi-likelihood method to accommodate a wider range of possible distributions and variances (Agresti 2002). The quasi-likelihood method is a generalization of the GLM (Paula 2004) that assumes a single relationship between the mean and variance rather than an a priori distribution for $Y$. Similar to the GLM, the quasi-likelihood model assumes a link function that is a linear predictor instead of a specific distribution of the response variable $Y$ (McCullagh \& Nelder 1989). It also assumes that $\operatorname{Var}(Y)=\phi \operatorname{Var}(\mu)$, where $\mu$ is the mean of $Y, V(\mu)$ is a new function of $\mu$ and $\phi$ is the dispersion parameter.

Grey leaf spot can severely affect susceptible cultivars, resulting in crop losses of greater than 0.80. In maize, the symptoms of grey leaf spot include irregular, rectangular grey spots that develop parallel to the leaf veins (Fantin et al. 2001; Fornasieri Filho 2007). According to Brito et al. (2007), the pathogen colonizes large areas of foliar tissue, reduces photosynthesis, induces early leaf senescence and decreases crop yield. Wind or raindrops can disseminate the pathogen. Because the spores remain on the stover after harvest, a management strategy must be adopted to reduce recontamination (Bhatia \& Munkvold 2002).

Thus, a maize variety carrying a large number of resistance genes is likely to have better yield in environments in which grey leaf spot is prevalent. Such genotypes must have stable, high yield with little variation in different environments (Tarakanovas \& Ruzgas 2006).

The objective of the present study was to evaluate and quantify the $G \times E$ interaction for response to grey leaf spot in maize using GAMMI models to identify genotypes that are resistant to grey leaf spot, adapted to specific environments, or both.

\section{MATERIALS AND METHODS}

Data pertaining to grey leaf spot severity in Brazil were collected from 36 maize cultivars evaluated in nine different environments in 2010/11. The experimental design in each environment was a randomized complete block with two replications. Plots consisted of four $5-\mathrm{m}$ rows spaced $0.70 \mathrm{~m}$ apart with experimental units of $14 \mathrm{~m}^{2}$. Fertilization, liming and other cultural practices were applied as required in each location and experimental area. Grey leaf spot severity was quantified as the percentage of diseased leaf area within each plot.

The locations in which the 36 genotypes $\left(\mathrm{G}_{1}\right.$ to $\left.\mathrm{G}_{36}\right)$ were evaluated by EMBRAPA are shown in Table 1. In the first stage of the present study, the Shapiro-Wilk multivariate normality test and the Bartlett test for homogeneity of variance were used to determine whether to apply an AMMI model or a GAMMI model to analyse the $G \times E$ interactions for incidence and severity of grey leaf spot in maize in these environments.

Additive main effects and multiplicative interaction model

The AMMI model was composed of additive and multiplicative components where $Y$ represents a vector of $n$ independently distributed observations that can be predicted by the categorical variables for genotypes and environments. The additive component, with fixed main effects for genotype $\left(\alpha_{i}\right)$ and environment $\left(\beta_{j}\right)$, was assumed to be a fixed effect, and inferences were restricted to the grey leaf spot response variables, disease incidence and severity (Searle et al. 1992).

A least-squares method was used to estimate these effects via a two-way ANOVA using the means matrix for $Y_{(g x e)}$. The multiplicative component was estimated by the singular value decomposition (SVD) of the residual matrix from the two-way ANOVA of the genotype-environment means $Y_{(g x e)}$. This matrix will be denoted as $R_{\text {(gxe) }}$. Generally, the SVD of a matrix $A$ is defined as the product of an orthogonal matrix $U$ by a diagonal matrix $S$ and the transpose of the orthogonal matrix $V$; thus, $A_{m n}=U_{m n} S_{m n} V_{n n}^{T}$. Required conditions are that $U^{T} U=I$ and $V^{T} V=I$; the columns of $U$ are orthonormal eigenvectors of $A A^{T}$; the columns of $V$ are orthonormal eigenvectors of $A^{T} A ; S$ is a diagonal matrix containing the square roots of eigenvalues from $U$ or $V$ in descending order; and $A=V S^{2} V^{T}$ (lentilucci 2003). 
Table 1. Codes and geographic coordinates for the locations in which maize genotypes were evaluated

\begin{tabular}{lllll}
\hline \hline Locations & Codes & Brazilian states* & Latitude (S) & Longitude (W) \\
\hline Campo Mourão & CM & Paraná-PR & $24^{\circ} 02^{\prime}$ & $52^{\circ} 22^{\prime}$ \\
Goiânia & GO & Goiás-GO & $16^{\circ} 40^{\prime}$ & $49^{\circ} 15^{\prime}$ \\
Goianésia & GS & Goiás-GO & $15^{\circ} 19^{\prime}$ & $49^{\circ} 07^{\prime}$ \\
Jataí & JT & Goiás-GO & $17^{\circ} 52^{\prime}$ & $51^{\circ} 42^{\prime}$ \\
Londrina & LD & Paraná-PR & $23^{\circ} 18^{\prime}$ & $51^{\circ} 09^{\prime}$ \\
Ponta Grossa & PG & Paraná-PR & $25^{\circ} 05^{\prime}$ & $50^{\circ} 09^{\prime}$ \\
Planaltina & PL & Goiás-DF & $15^{\circ} 27^{\prime}$ & $47^{\circ} 36^{\prime}$ \\
Patos de Minas & PM & Minas Gerais-MG & $18^{\circ} 34^{\prime}$ & $46^{\circ} 31^{\prime}$ \\
São Sebastião do Paraíso & SP & Minas Gerais-MG & $20^{\circ} 55^{\prime}$ & $46^{\circ} 59^{\prime}$ \\
\hline \hline
\end{tabular}

* State name and state abbreviation.

Therefore, the model equation for the ith genotype in the jth environment in the $r$ th block is (Gauch \& Zobel 1988):

$$
Y_{i j r}=\underbrace{\mu+\alpha_{i}+\beta_{j}+\rho_{r(j)}}_{\text {additive terms }}+\underbrace{\sum_{h=1}^{p} \lambda_{h} \gamma_{i h} \delta_{j h}}_{\text {multiplicative terms }}+\varepsilon_{i j r}
$$

where $Y_{i j r}$ is the phenotypic trait (i.e., the proportion of plants affected by grey leaf spot) of genotype $i$ in environment $j$ for replicate $r ; \mu$ is the grand mean; $\alpha_{i}$ is the fixed effect for genotype $i$, where $i=1,2, \ldots, g$; $\beta_{j}$ is the fixed effect for the environment $j$, where $j=1,2, \ldots, e ; \lambda_{h}$ is the singular value for the interaction principal component (IPC) axis $k ; \gamma_{i h}$ and $\delta_{j h}$ are the IPC scores (i.e., the left and right singular vectors) for genotype and environment, respectively, for axis $k ; \rho_{r(j)}$ is the effect of the $r$ th block in the $j$ th environment; $r$ is the number of blocks; $p$ is the rank of the $R_{\text {(gxe) }}$ matrix that corresponds to the number of main effects from the interaction $(\mathrm{PCl})$ retained by the residual matrix, $p=\min (\mathrm{g}-1, \mathrm{e}-1) ;(\alpha \beta)_{i j}=$ $\sum_{h=1}^{p} \lambda_{h} \gamma_{i h} \delta_{j h}$ is the specific interaction of the $i$ th genotype with the $j$ th environment and $\varepsilon_{i j r}$ is the experimental error that is assumed to be independently and normally distributed with a mean of zero and variance $\sigma^{2}, \varepsilon_{i j r} \sim N\left(0, \sigma^{2}\right)$. The decomposition of the residual matrix into singular values (SVD) permits the partitioning of the least squares from the elements of the $R_{\text {(gxe) }}$ matrix by reducing the number of axes, or $K<p$ such that the model remains informative, where $K$ is the number of axes or PC retained by the model, but with fewer degrees of freedom. This partition is:

$$
\sum_{h=1}^{p} \lambda_{h} \gamma_{i h} \delta_{j h}=\sum_{h=1}^{K} \lambda_{h} \gamma_{i h} \delta_{j h}+\sum_{h=1+K}^{p} \lambda_{h} \gamma_{i h} \delta_{j h},
$$

where $\sum_{h=1+K}^{p} \lambda_{h} \gamma_{i h} \delta_{j h}=\varphi_{i j r}$ quantifies the disturbance and $\varphi_{i j r}$ is the residual containing all of the multiplicative terms not included in the model.

Therefore, using the least-squares approximation to the $R_{(g x e)}$ matrix by the first $n$ components of the SVD, the reduced model nijr is estimated by:

$$
\hat{Y}_{i j r}=\underbrace{\hat{\mu}+\hat{\alpha}_{i}+\hat{\beta}_{j}+\hat{\rho}_{r(j)}}_{\text {additive terms }}+\underbrace{\sum_{h=1}^{K} \lambda_{h} \gamma_{i h} \delta_{j h}}_{\text {multiplicative terms }}
$$

The PCA permits the components from the interaction to capture the decreasing proportion of the variation that is present in matrix $G E$, or $\lambda_{1}^{2} \geq \lambda_{2}^{2} \geq \cdots \geq \lambda_{K}^{2}$. A sufficient number of components $(K)$ to represent the target model can be identified using Gollob's test (Table 2) (Gollob 1968).

\section{Generalized linear models}

When a distribution is non-normal, GLMs expand the possibilities for statistical modelling. These models allow fitting of $n$ random variables $y_{i}$, where $i=1,2, \ldots$, $n$, that are independently distributed with mean $\mu_{i}$ and an exponential probability density function. These random variables are associated with the explanatory variables $x_{j}, j=1,2, \ldots, p$ by means of a link function $g$ $\left(\mu_{i}\right)$ designated as the linear predictor $\left(\eta_{i}\right)$ that is monotonic and differentiable such that:

$\eta_{\mathrm{i}}=g\left(\mu_{i}\right)=\sum_{\mathrm{j}=1}^{\mathrm{p}} x_{\mathrm{ij}} \psi_{\mathrm{j}}$

where $\psi_{j}$ represents the coefficients of the linear predictor.

The maximum-likelihood method is the most useful method for estimating the vector of the unknown 
Table 2. Complete variance analyses of the means according to Gollob (1968)

\begin{tabular}{|c|c|c|}
\hline Source of variation & D.F. (Gollob) & $\begin{array}{l}\text { Deviance } \\
\text { (Gollob) }\end{array}$ \\
\hline Blocks/environment (E) & $e(j-1)$ & Deviance $(\mathrm{R} \mid \mathrm{E})$ \\
\hline Genotype (G) & $g-1$ & Deviance $_{G}$ \\
\hline Environment (E) & e-1 & Deviance $_{\mathrm{E}}$ \\
\hline $\mathrm{G} \times \mathrm{E}$ interaction & $(g-1)(e-1)$ & Deviance $_{\mathrm{GE}}$ \\
\hline Axis $_{1}$ & $g+e-1-(2 \times 1)$ & $\lambda_{1}^{2}$ \\
\hline $\mathrm{Axis}_{2}$ & $g+e-1-(2 \times 2)$ & $\lambda_{2}^{2}$ \\
\hline$\cdots$ & $\cdots$ & $\cdots$ \\
\hline $\mathrm{Axis}_{k}$ & $g+e-1-(2 \times j)$ & $\lambda_{k}^{2}$ \\
\hline Plot error & $e(g-1)(j-1)$ & Deviance $_{\text {Plot error }}$ \\
\hline Total & gej-1 & Deviance Total \\
\hline
\end{tabular}

parameters of the linear predictor $\psi_{j}$. Cordeiro \& Demétrio (2008) explained that the robust and fast GLM algorithm rarely fails to converge. However, when this does happen, the fitting procedure must be restarted using the current estimate as the starting value for another model.

The deviance function derived from the likelihood ratio statistic tests the significance of the coefficients of the linear predictor. Therefore, in a sequence of $k$ nested models (which have the same probability distribution and link function, but the linear component $M_{0}$ is a special case of the general linear component $M_{1}$ ) (Dobson 2002), tests of significance are performed using an analysis of deviance (ANODEV) table. Thus the deviance function from the GLMs is analogous to the residual squared sums from least squares. Standardized Pearson residuals, standardized deviance residuals, and Cook's distance measures were used to diagnoses in the quasi-likelihood models.

Quasi-likelihood models

Quasi-likelihood has been used due to the characteristics of the data and the model. Although the GLM represents a great advance in statistical modelling because it allows the fitting of a large number of models, in some instances the choice of an exponential model is not adequate (McCullagh \& Nelder 1989), so Wedderburn (1974) proposed quasilikelihood estimation. Assuming that $\operatorname{Var}(\mu)$ is a known function of the mean, and $\phi$ is the dispersion parameter, the quasi-likelihood function for every observation is

$Q_{i}=Q_{i}(y ; \mu)=\int_{y_{i}}^{\mu_{i}} \frac{y_{i}-t}{\phi \cdot \operatorname{Var}(t)} d t, \quad y_{i} \leq t \leq \mu_{i}$

Inference in quasi-likelihood models is similar to that in GLM because quasi-likelihood estimates maximize $Q$ or solve the following system of equations:

$\sum_{i=1}^{n} \frac{\left(y_{i}-\mu_{i}\right)}{\phi V\left(\mu_{i}\right)} \frac{\partial \mu_{i}}{\partial \psi_{j}}=0, j=1, \ldots, p$

and

$\sum_{i=1}^{n} \frac{\left(y_{i}-\mu_{i}\right) x_{i j}}{\phi V\left(\mu_{i}\right)} \frac{\partial \mu_{i}}{\partial \eta_{i}}=0$

In the first system, $\mu_{i}=g^{-1}\left(\eta_{i}\right)=g^{-1}\left(z_{i}^{T} \psi_{j}\right)=h\left(x_{i}^{T} \psi_{j}\right)$ and this expression are based on the GLM theory. The dispersion $\phi$ is estimated using the method of moments on the residual vector $(Y-\hat{\mu})$ :

$\hat{\phi}=\frac{1}{n-p} \sum_{i=1}^{n} \frac{\left(y_{i}-\hat{\mu}_{i}\right)^{2}}{V\left(\hat{\mu}_{i}\right)}=\frac{\chi^{2}}{n-p}$

where $\chi^{2}$ is Pearson's generalized chi-square statistic for goodness-of-fit, $n$ is the number of observations, and $p$ is the number of parameters $\left(\psi_{j}\right)$. The generalized function can be estimated in a similar manner to the deviance function, using the difference between the quasi-likelihood logarithm of the current and the saturated models:

$$
\begin{aligned}
D(y ; \hat{\mu}) & =2 \phi\{Q(y ; y)-Q(\hat{\mu} ; y)\} \\
& =-2 \phi\{Q(\hat{\mu} ; y)-Q(y ; y)\}
\end{aligned}
$$

Because the contribution from the saturated model is zero, then:

$$
\begin{aligned}
D(y ; \hat{\mu}) & =-2 \phi Q=-2 \phi \sum \int_{y_{i}}^{\mu_{i}} \frac{y_{i}-t}{\phi V(t)} d t \\
& =-2 \sum \int_{y_{i}}^{\mu_{i}} \frac{y_{i}-t}{V(t)} d t
\end{aligned}
$$

Thus, the quasi-deviance function does not depend on the dispersion parameter $\phi$. The quasi-deviance function $D(y ; \hat{\mu}) / \phi$ is compared with the percentiles of the $\chi^{2}$ distribution with $(n-p)$ degrees of freedom, although the null distribution of $\phi^{-1} D(y ; \hat{\mu})$ is not usually known (Paula 2004).

Generalized additive main effects and multiplicative interaction

The GAMMI theory requires the same basic assumptions as the GLMs. The response variable $Y$ must be 
independently distributed and have a known exponential family distribution, and $p$ associated explanatory variables $X_{j}$, where $j=1,2, \ldots, p$ are determined by a link function $g\left(\mu_{i}\right)$ that designates a linear predictor $\eta_{i}$ that is monotonic and differentiable such that:

$\eta_{i}=g\left(\mu_{i}\right)=\sum_{j=1}^{p} X_{i j} \psi_{j}$

These linear predictors have been useful to estimate the mean severity of grey leaf spot. Because the link function was the logit in which $\eta=g(\mu)=\log (\mu / 1-\mu)$, the mean proportion of disease was estimated by the relationship

$$
g^{-1}\left(\eta_{i j r}\right)=\frac{\exp \left(\mu+\alpha_{i}+\beta_{j}+\rho_{r(j)}+\sum_{h=1}^{K} \lambda_{h} \gamma_{i h} \delta_{j h}\right)}{1+\exp \left(\mu+\alpha_{i}+\beta_{j}+\rho_{r(j)}+\sum_{h=1}^{K} \lambda_{h} \gamma_{i h} \delta_{j h}\right)}
$$

where $K$ is the number of axes considered.

The GAMMI model is applied using van Eeuwijk's algorithm adapted from Sumertajaya (2007) in R software version 3.0.2 (R Development Core Team 2013) using the $\mathrm{R}$ package gnm (generalized nonlinear models) (Turner \& Firth 2009). This algorithm uses iterative alternating generalized regression of rows and columns to estimate the parameters. The first step in determining the appropriate model is to identify the distribution and handling of the experimental data. An error plot should be used to visualize whether the data have, for example, a Poisson or binomial distribution instead of a normal distribution. The second step is to fit the GAMMI model, in which each regression includes a GLM class that is arrived at iteratively. This algorithm involves convergence in row regression, in column regression, and in alternating regression (Hadi et al. 2010). If the model converges, then ANODEV may then be performed. Finally, the data matrix is represented as a biplot. Figure 1 shows the algorithm necessary for applying the GAMMI model.

To determine the number of axes or the number of multiplicative terms in a GAMMI model, a generalization of the AMMI method via the tests described below may be used. The $F$ test does not require a special table and is easy to calculate. The statistic used is $F=($ Dev. restricted/D.F. sv restricted)(Dev. full/ D.F. full) $/ \hat{\phi}$, which approximates the $F$ (D.F.source of variation; D.F.error) distribution. Where: Dev. : deviance, $\hat{\phi}$ is the dispersion parameter from quasi-likelihood estimation, D.F..sv: degrees of freedom from source of variation that is being tested.
The test proposed by Gollob (1968) allocates $(g-1)(e-1)-(2 k-1)=g+e-1-2 k$ degrees of freedom to the eigenvalues associated with the $k$ th axis, where $k=1,2, \ldots, n$ and $n=\operatorname{minimum}(g-1, \mathrm{e}-1)$, which corresponds to the difference between the number of parameters to be estimated and the number of factors applied. Thus, the mean deviance is tested against the estimated error.

Stability is the maintenance or predictability of the response variable in various environments (Annicchiarico et al. 2005; Cruz et al. 2006). For the incidence or severity of disease, a genotype is considered to be stable when its disease severity percentage is low and constant with respect to environmental variation under both specific and broad conditions. Stability is estimated by analysing the magnitude and sign of the biplot scores corresponding to the selected GAMMI model. Genotypes and environments with low (near zero) scores are considered stable, which is expected for genotypes and environments that have a small contribution to the overall interaction (Duarte \& Vencovsky 1999).

The adaptability of a genotype indicates its ability to take advantage of environmental effects to ensure a high level of productivity. Adaptability is predicted as a function of the responses for each combination of genotype and environment in the model selected by GAMMI IPCAk (axis $k$ : axis of interaction PCA). The correlation between cultivars and the environment is based on the angles between vectors determined by coordinates of the interaction (axis 1 , axis 2 ) and the vertex. The cosine of the two vectors indicates the level of correlation between two corresponding variables (Rencher 2002). Therefore, a small angle indicates highly positively correlated variables, perpendicular vectors indicate non-correlated variables, and an angle greater than $90^{\circ}$ indicates a negative correlation.

\section{RESULTS}

Box plots of grey leaf spot incidence showed strong evidence of asymmetric disease severity and discrepancies in the data for the distribution of disease by location and genotype (Fig. 2).

The results of the Shapiro-Wilk test $(W)$ indicated that the data were not normally distributed $(W=$ $\left.0 \cdot 4974, P<2 \cdot 2 \times 10^{-16}\right)$. Similarly, the hypothesis of homogeneous variance was rejected based on results of the Bartlett test, both for genotype (D.F.= $35 ; \chi^{2}=520 \cdot 30 ; P<2 \cdot 2 \times 10^{-16}$ ) and location (D.F. $=$ $\left.8 ; \chi^{2}=682 \cdot 88 ; P<2 \cdot 2 \times 10^{-16}\right)$. 


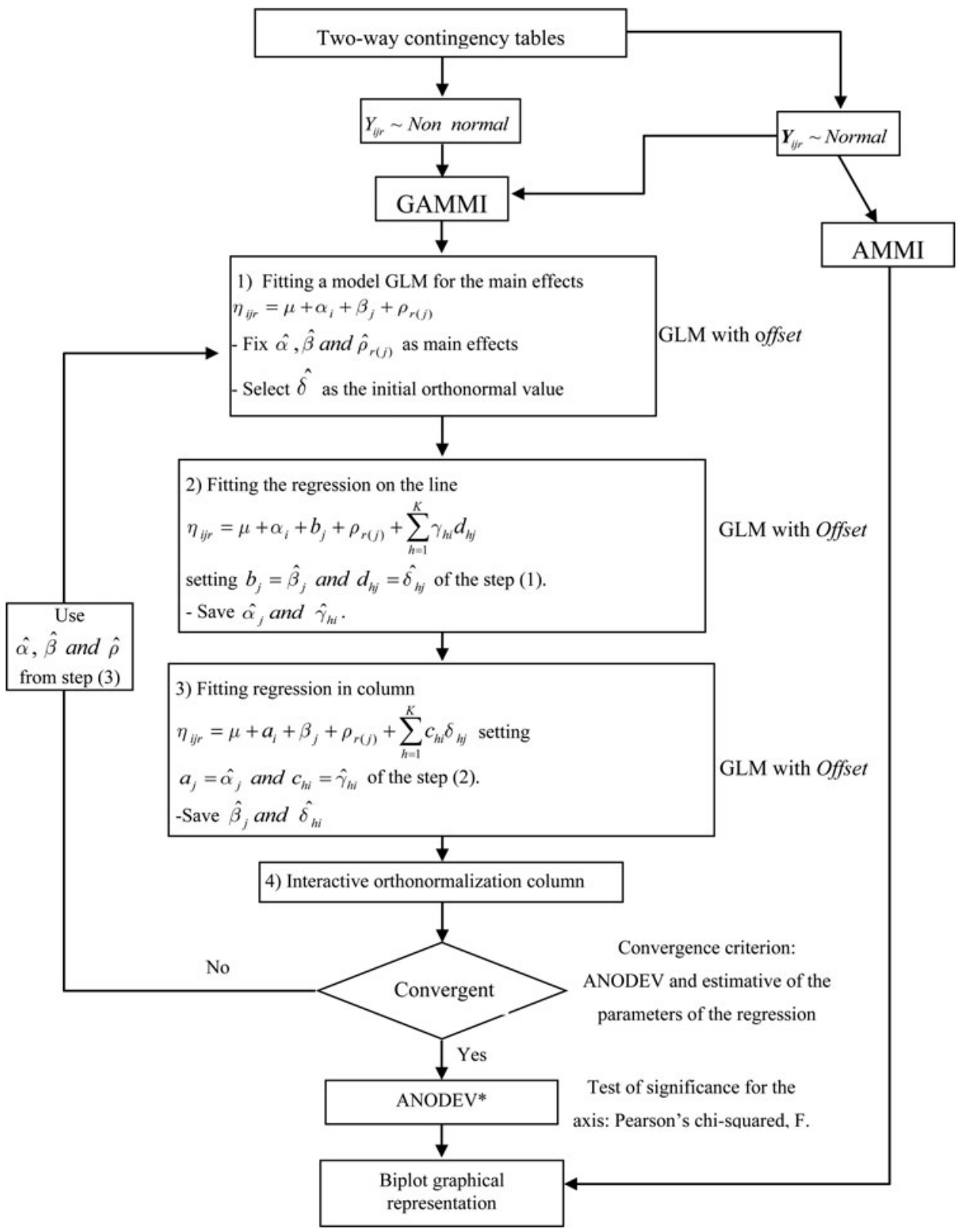

Fig. 1. van Eeuwijk's algorithm for modelling GAMMI, adapted from Sumertajaya (2007). *Analysis of Deviance (ANODEV).

Thereafter, the first step in applying the GAMMI methodology was to determine the means, variances and coefficients of variation (CV) for the severity of grey leaf spot. Some discrepant values for location and genotype were detected. The highest disease severity levels were detected in Campo Mourão $(36 \cdot 85 \%)$ and Patos de Minas $(6 \cdot 67 \%)$, and the lowest levels were detected in Goianésia (0.61\%) and Londrina (1.45\%). Campo Mourão had the lowest coefficient of variation (70.6\%) for disease severity, while those for Planaltina (329.5\%) and São Sebastião do Paraíso (260.9\%) were very high.
Coefficient of variation values for other locations ranged from $83 \cdot 4$ to $250 \cdot 7 \%$. Moreover, there was large variability in disease severity among genotypes. Means for grey leaf spot severity ranged from $0.9\left(\mathrm{G}_{15}\right.$ and $\left.\mathrm{G}_{10}\right)$ to $34.5 \%\left(\mathrm{G}_{29}\right)$ and the $\mathrm{CV}$ values ranged from $81 \cdot 6$ to $283 \cdot 9 \%$ (Table 3 ).

The models were fit using quasi-likelihood with the logit link function. The first model (model 1 ) has the variance function $(\mu)=\mu(1-\mu)$. The second model (model 2) was based on Wedderburn (1974), in which the variance function is equal to the square of the variance of the binomial distribution, $\operatorname{Var}(\mu)=[\mu$ 


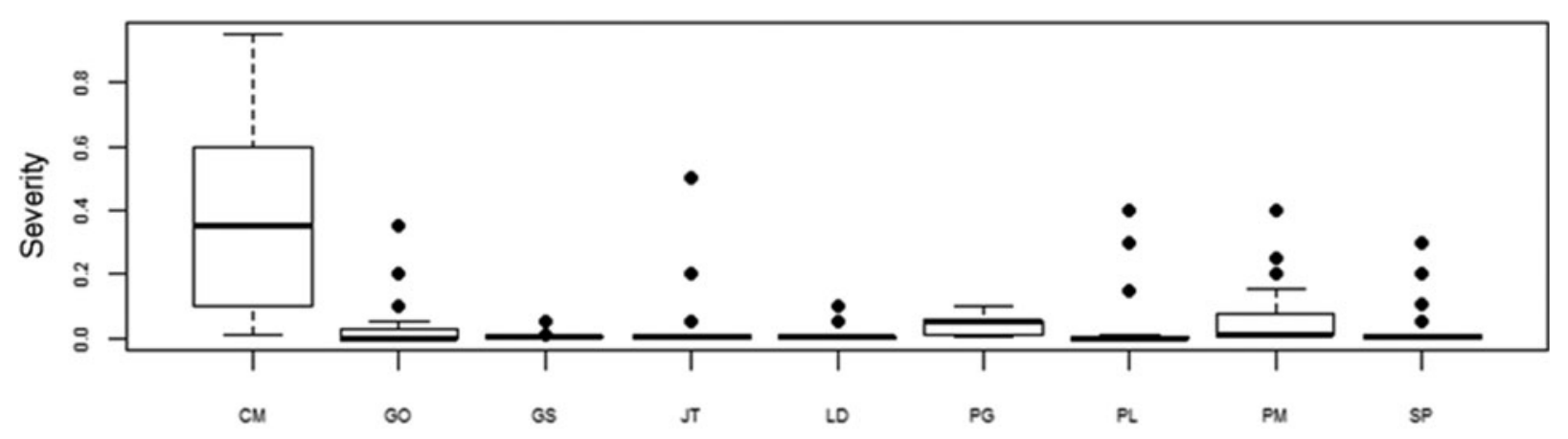

Distribution by locations

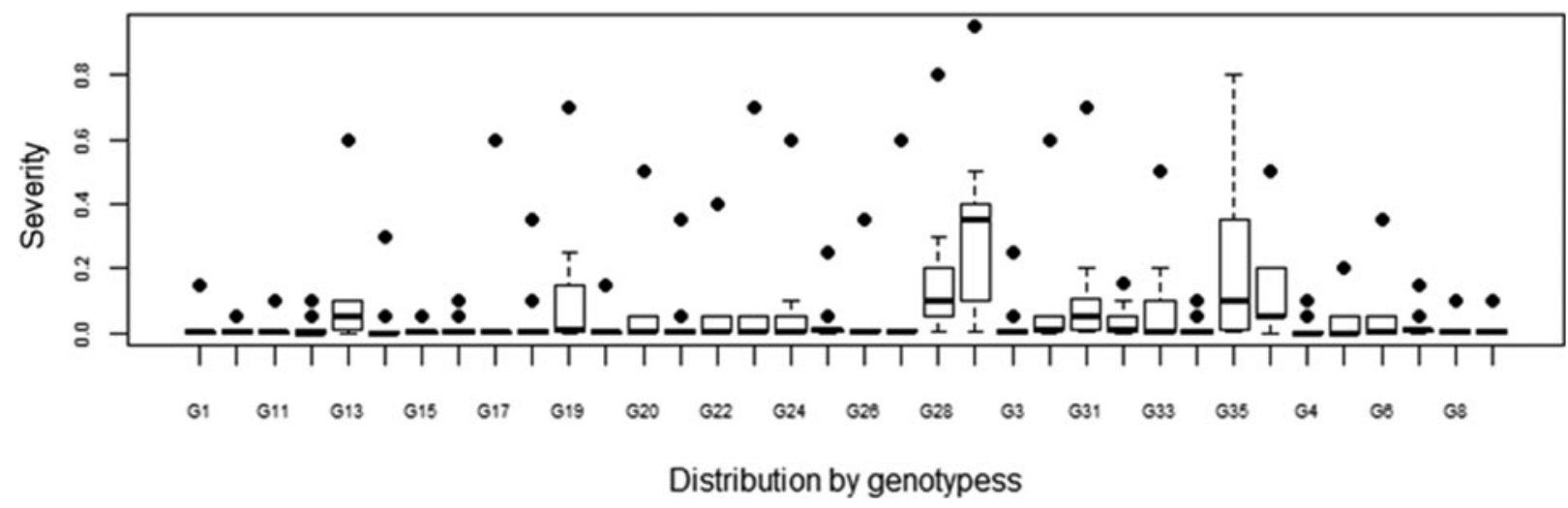

Fig. 2. Box plot of environments and genotypes showing the distribution of grey leaf spot severity. Locations: Campo Mourão $(\mathrm{CM})$, Goiânia (GO), Goianésia (GS), Jataí (JT), Londrina (LD), Ponta Grossa (PG), Planaltina (PL), Patos de Minas (PM) and São Sebastião do Paraíso (SP).

$(1-\mu)]^{2}$. The logit link function is the linear predictor model.

The quasi-likelihood models are depicted in Fig. 3. Graphs of the standardized deviance residuals, linear predictor, index and normal QQ plot for model 1 are depicted in the first column, and those representing model 2 are depicted in the second column. Model 2 fit the data better with a more normal distribution of residuals (Fig. 3).

The ANODEV with the logit link function and variance function $\operatorname{Var}(\mu)=[\mu(1-\mu)]^{2}$ was significant for genotype and environment and also for the two first axes of the $\mathrm{G} \times \mathrm{E}$ interaction (Table 4). The relative contribution of genotype and environment to the interaction is shown in Fig. 4, and the genotypes with desirable low mean disease severity are shown in Fig. 5. Figure 4 describes the variability associated with the first two axes and Fig. 5 shows the relationship between the average severity of grey leaf spot and the first term of the interaction.

The first two components of the GAMMI graphic that contain the average severity of grey leaf spot and the first term of the $\mathrm{G} \times \mathrm{E}$ interaction identified
Campo Mourão, Goianésia, Londrina and São Sebastião do Paraíso as locations in which the average disease severity of genotypes is less variable. The scores from these environments are close to the vertex, which indicates minimal variation between genotypes within each environment. However, the disease severity responses of these locations were distinct. For example, genotypes in Campo Mourão had low variability and high severity of grey leaf spot (36.8\%).

The contributions of Goianésia, Londrina and São Sebastião do Paraíso to the $\mathrm{G} \times \mathrm{E}$ interaction were relatively low, as indicated by average disease severities of $0.6,1.4$ and $2.3 \%$, respectively, in these regions (Fig. 4 and Table 3). The genotypes $G_{9}, G_{1}$ and $\mathrm{G}_{17}$ had average disease severities of 1.4, 1.9 and $7.0 \%$, respectively, which were close to the vertex. Therefore, these genotypes can be considered stable because of their low variability for disease severity.

Although genotype $\mathrm{G}_{17}$ is stable, it had greater grey leaf spot severity than did $G_{9}$ and $G_{1}$ (Fig. 5 and Table 3); thus, only $G_{9}$ and $G_{1}$ can be recommended 
Table 3. Mean values of grey leaf spot severity estimated from two replications of 36 maize cultivars grown in nine locations during the 2010/11 growing season

\begin{tabular}{|c|c|c|c|c|c|c|c|c|c|c|c|c|}
\hline \multirow[b]{2}{*}{ Genotypes } & \multicolumn{9}{|c|}{ Locations } & \multirow[b]{2}{*}{ Mean } & \multirow[b]{2}{*}{ Variance } & \multirow[b]{2}{*}{ CV\% } \\
\hline & $\mathrm{CM}$ & $\mathrm{GO}$ & GS & JT & LD & PG & $P L$ & PM & SP & & & \\
\hline $\mathrm{G}_{1}$ & $0 \cdot 150$ & $0 \cdot 000$ & 0.005 & $0 \cdot 000$ & $0 \cdot 000$ & $0 \cdot 010$ & $0 \cdot 000$ & 0.005 & 0.005 & $0 \cdot 019$ & $0 \cdot 0024$ & $251 \cdot 6$ \\
\hline $\mathrm{G}_{2}$ & $0 \cdot 150$ & 0.000 & 0.000 & 0.000 & 0.005 & $0 \cdot 010$ & 0.005 & 0.005 & 0.005 & $0 \cdot 020$ & 0.0024 & $244 \cdot 2$ \\
\hline $\mathrm{G}_{3}$ & $0 \cdot 250$ & 0.005 & $0 \cdot 005$ & $0 \cdot 000$ & 0.005 & $0 \cdot 010$ & $0 \cdot 000$ & 0.055 & $0 \cdot 000$ & 0.037 & 0.0067 & $223 \cdot 0$ \\
\hline $\mathrm{G}_{4}$ & $0 \cdot 100$ & $0 \cdot 000$ & $0 \cdot 000$ & 0.000 & 0.005 & 0.055 & $0 \cdot 000$ & 0.005 & $0 \cdot 000$ & $0 \cdot 018$ & $0 \cdot 0013$ & $192 \cdot 5$ \\
\hline $\mathrm{G}_{5}$ & $0 \cdot 200$ & $0 \cdot 000$ & $0 \cdot 005$ & $0 \cdot 000$ & $0 \cdot 000$ & 0.055 & $0 \cdot 000$ & $0 \cdot 055$ & $0 \cdot 000$ & 0.035 & 0.0044 & $188 \cdot 5$ \\
\hline $\mathrm{G}_{6}$ & $0 \cdot 350$ & 0.000 & 0.005 & $0 \cdot 000$ & $0 \cdot 000$ & 0.055 & $0 \cdot 000$ & 0.055 & 0.005 & $0 \cdot 052$ & 0.0130 & $218 \cdot 0$ \\
\hline $\mathrm{G}_{7}$ & $0 \cdot 150$ & 0.005 & 0.005 & 0.005 & $0 \cdot 010$ & $0 \cdot 010$ & $0 \cdot 000$ & $0 \cdot 055$ & $0 \cdot 010$ & $0 \cdot 028$ & 0.0024 & $175 \cdot 1$ \\
\hline $\mathrm{G}_{8}$ & $0 \cdot 100$ & $0 \cdot 000$ & $0 \cdot 010$ & 0.005 & 0.005 & $0 \cdot 010$ & $0 \cdot 000$ & $0 \cdot 010$ & $0 \cdot 000$ & $0 \cdot 016$ & $0 \cdot 0010$ & $204 \cdot 8$ \\
\hline $\mathrm{G}_{9}$ & $0 \cdot 100$ & $0 \cdot 000$ & $0 \cdot 000$ & $0 \cdot 000$ & $0 \cdot 005$ & $0 \cdot 010$ & $0 \cdot 000$ & $0 \cdot 010$ & $0 \cdot 005$ & $0 \cdot 014$ & 0.0010 & $223 \cdot 0$ \\
\hline $\mathrm{G}_{10}$ & $0 \cdot 010$ & $0 \cdot 000$ & 0.005 & 0.000 & 0.005 & $0 \cdot 050$ & $0 \cdot 000$ & $0 \cdot 010$ & $0 \cdot 000$ & 0.009 & 0.0003 & $179 \cdot 1$ \\
\hline $\mathrm{G}_{11}$ & $0 \cdot 100$ & 0.005 & 0.005 & 0.000 & 0.005 & 0.005 & $0 \cdot 000$ & $0 \cdot 010$ & $0 \cdot 000$ & $0 \cdot 014$ & $0 \cdot 0010$ & $222 \cdot 3$ \\
\hline $\mathrm{G}_{12}$ & $0 \cdot 100$ & $0 \cdot 000$ & $0 \cdot 000$ & $0 \cdot 000$ & $0 \cdot 000$ & 0.055 & $0 \cdot 000$ & $0 \cdot 010$ & $0 \cdot 000$ & $0 \cdot 018$ & $0 \cdot 0013$ & 192.9 \\
\hline $\mathrm{G}_{13}$ & $0 \cdot 600$ & $0 \cdot 000$ & $0 \cdot 010$ & 0.055 & 0.055 & $0 \cdot 100$ & 0.005 & $0 \cdot 100$ & $0 \cdot 010$ & $0 \cdot 104$ & 0.0361 & $183 \cdot 0$ \\
\hline $\mathrm{G}_{14}$ & $0 \cdot 300$ & $0 \cdot 000$ & $0 \cdot 000$ & $0 \cdot 000$ & $0 \cdot 000$ & $0 \cdot 055$ & $0 \cdot 000$ & $0 \cdot 005$ & $0 \cdot 000$ & $0 \cdot 040$ & 0.0098 & $247 \cdot 2$ \\
\hline $\mathrm{G}_{15}$ & 0.055 & 0.000 & 0.005 & 0.005 & $0 \cdot 000$ & $0 \cdot 010$ & $0 \cdot 000$ & 0.005 & 0.000 & 0.009 & 0.0003 & $197 \cdot 9$ \\
\hline $\mathrm{G}_{16}$ & $0 \cdot 100$ & $0 \cdot 000$ & $0 \cdot 000$ & 0.005 & $0 \cdot 000$ & $0 \cdot 010$ & 0.005 & 0.055 & $0 \cdot 005$ & $0 \cdot 020$ & 0.0012 & $173 \cdot 1$ \\
\hline $\mathrm{G}_{17}$ & $0 \cdot 600$ & 0.005 & 0.005 & $0 \cdot 010$ & $0 \cdot 000$ & 0.005 & $0 \cdot 000$ & 0.005 & $0 \cdot 000$ & $0 \cdot 070$ & 0.0395 & 283.9 \\
\hline $\mathrm{G}_{18}$ & $0 \cdot 350$ & $0 \cdot 000$ & $0 \cdot 005$ & 0.005 & $0 \cdot 000$ & $0 \cdot 100$ & $0 \cdot 000$ & $0 \cdot 010$ & $0 \cdot 010$ & $0 \cdot 053$ & 0.0134 & $216 \cdot 7$ \\
\hline $\mathrm{G}_{19}$ & $0 \cdot 700$ & $0 \cdot 000$ & 0.055 & $0 \cdot 010$ & $0 \cdot 005$ & $0 \cdot 010$ & $0 \cdot 150$ & $0 \cdot 250$ & $0 \cdot 005$ & $0 \cdot 132$ & 0.0528 & $174 \cdot 4$ \\
\hline $\mathrm{G}_{20}$ & $0 \cdot 500$ & 0.005 & 0.005 & 0.005 & $0 \cdot 005$ & $0 \cdot 055$ & $0 \cdot 000$ & 0.055 & $0 \cdot 000$ & $0 \cdot 070$ & 0.0265 & $232 \cdot 6$ \\
\hline $\mathrm{G}_{21}$ & $0 \cdot 350$ & $0 \cdot 000$ & 0.005 & $0 \cdot 010$ & $0 \cdot 000$ & 0.055 & $0 \cdot 000$ & $0 \cdot 010$ & 0.005 & $0 \cdot 048$ & $0 \cdot 0131$ & $236 \cdot 4$ \\
\hline $\mathrm{G}_{22}$ & $0 \cdot 400$ & $0 \cdot 000$ & $0 \cdot 000$ & $0 \cdot 050$ & $0 \cdot 050$ & 0.005 & 0.005 & $0 \cdot 010$ & 0.005 & $0 \cdot 058$ & $0 \cdot 0168$ & $222 \cdot 0$ \\
\hline $\mathrm{G}_{23}$ & $0 \cdot 700$ & $0 \cdot 000$ & $0 \cdot 005$ & 0.055 & $0 \cdot 005$ & $0 \cdot 055$ & $0 \cdot 005$ & $0 \cdot 005$ & $0 \cdot 005$ & 0.093 & 0.0523 & $246 \cdot 5$ \\
\hline $\mathrm{G}_{24}$ & $0 \cdot 600$ & 0.000 & 0.005 & $0 \cdot 010$ & 0.005 & $0 \cdot 100$ & 0.005 & $0 \cdot 055$ & 0.005 & 0.087 & $0 \cdot 0381$ & $223 \cdot 8$ \\
\hline $\mathrm{G}_{25}$ & $0 \cdot 250$ & 0.055 & $0 \cdot 000$ & 0.005 & $0 \cdot 005$ & $0 \cdot 010$ & $0 \cdot 000$ & $0 \cdot 010$ & $0 \cdot 010$ & $0 \cdot 038$ & 0.0066 & $211 \cdot 2$ \\
\hline $\mathrm{G}_{26}$ & $0 \cdot 350$ & 0.005 & 0.005 & $0 \cdot 010$ & $0 \cdot 000$ & $0 \cdot 010$ & 0.005 & $0 \cdot 010$ & 0.005 & $0 \cdot 044$ & $0 \cdot 0131$ & $257 \cdot 6$ \\
\hline $\mathrm{G}_{27}$ & $0 \cdot 600$ & 0.005 & $0 \cdot 010$ & $0 \cdot 005$ & $0 \cdot 005$ & 0.005 & $0 \cdot 010$ & $0 \cdot 010$ & $0 \cdot 005$ & 0.073 & 0.0391 & $271 \cdot 6$ \\
\hline $\mathrm{G}_{28}$ & $0 \cdot 800$ & $0 \cdot 100$ & $0 \cdot 005$ & $0 \cdot 200$ & $0 \cdot 005$ & $0 \cdot 055$ & $0 \cdot 300$ & $0 \cdot 100$ & $0 \cdot 200$ & $0 \cdot 196$ & 0.0609 & $125 \cdot 8$ \\
\hline $\mathrm{G}_{29}$ & 0.950 & $0 \cdot 350$ & 0.005 & $0 \cdot 500$ & $0 \cdot 100$ & $0 \cdot 100$ & $0 \cdot 400$ & $0 \cdot 400$ & $0 \cdot 300$ & $0 \cdot 345$ & 0.0792 & $81 \cdot 6$ \\
\hline $\mathrm{G}_{30}$ & $0 \cdot 600$ & 0.055 & $0 \cdot 010$ & $0 \cdot 010$ & $0 \cdot 010$ & 0.055 & $0 \cdot 000$ & 0.055 & 0.005 & 0.089 & 0.0373 & $217 \cdot 2$ \\
\hline $\mathrm{G}_{31}$ & $0 \cdot 700$ & $0 \cdot 200$ & 0.005 & 0.005 & $0 \cdot 050$ & 0.055 & $0 \cdot 010$ & $0 \cdot 105$ & 0.055 & $0 \cdot 132$ & 0.0492 & $168 \cdot 4$ \\
\hline $\mathrm{G}_{32}$ & $0 \cdot 100$ & $0 \cdot 050$ & $0 \cdot 010$ & $0 \cdot 005$ & $0 \cdot 010$ & 0.005 & $0 \cdot 000$ & $0 \cdot 155$ & $0 \cdot 010$ & $0 \cdot 038$ & 0.0030 & $141 \cdot 9$ \\
\hline $\mathrm{G}_{33}$ & $0 \cdot 500$ & 0.050 & 0.000 & $0 \cdot 200$ & 0.005 & 0.005 & 0.005 & $0 \cdot 100$ & 0.005 & 0.097 & 0.0273 & $170 \cdot 9$ \\
\hline
\end{tabular}


for use in maize breeding programmes. The genotypes shown in Fig. 4 that appear in the upper or lower quadrants on the left showed the lowest severity of grey leaf spot. The decreasing rank order of disease severity for genotypes in the upper quadrant was $\mathrm{G}_{12}\left(6^{\mathrm{a}}\right)>\mathrm{G}_{14}\left(17^{\mathrm{a}}\right)>\mathrm{G}_{4}\left(7^{\mathrm{a}}\right)>\mathrm{G}_{10}\left(1^{\mathrm{a}}\right)>\mathrm{G}_{5}\left(13^{\mathrm{a}}\right)>$ $\mathrm{G}_{20}\left(23^{\mathrm{a}}\right)>\mathrm{G}_{3}\left(14^{\mathrm{a}}\right)>\mathrm{G}_{11}\left(3^{\mathrm{a}}\right)>\mathrm{G}_{6}\left(20^{\mathrm{a}}\right)>\mathrm{G}_{7}\left(12^{\mathrm{a}}\right)>$ and $\mathrm{G}_{9}\left(4^{\mathrm{a}}\right)$. The decreasing rank order of disease severity for genotypes in the lower quadrant was $\mathrm{G}_{34}$ $\left(9^{\mathrm{a}}\right)>\mathrm{G}_{18}\left(21^{\mathrm{a}}\right)>\mathrm{G}_{21}\left(19^{\mathrm{a}}\right)>\mathrm{G}_{8}\left(5^{\mathrm{a}}\right)>\mathrm{G}_{15}\left(2^{\mathrm{a}}\right)>\mathrm{G}_{24}$ $\left(26^{\mathrm{a}}\right)>\mathrm{G}_{13}\left(30^{\mathrm{a}}\right)>\mathrm{G}_{1}\left(8^{\mathrm{a}}\right)>$ and $\mathrm{G}_{17}\left(24^{\mathrm{a}}\right)$. The genotypes $G_{32}\left(15^{\mathrm{a}}\right)>\mathrm{G}_{31}\left(31^{\mathrm{a}}\right)>\mathrm{G}_{35}\left(35^{\mathrm{a}}\right)>\mathrm{G}_{30}\left(27^{\mathrm{a}}\right)>$ $\mathrm{G}_{25}\left(16^{\mathrm{a}}\right)>$ and $\mathrm{G}_{36}\left(33^{\mathrm{a}}\right)$ in the upper right quadrant were sequentially closest to the vertex of the $1^{\circ}$ and $2^{\circ}$ axes and had the highest grey leaf spot severity. The genotypes $\mathrm{G}_{28}\left(34^{\mathrm{a}}\right)>\mathrm{G}_{29}\left(36^{\mathrm{a}}\right)>\mathrm{G}_{19}\left(32^{\mathrm{a}}\right)>\mathrm{G}_{23}$ $\left(28^{\mathrm{a}}\right)>\mathrm{G}_{33}\left(29^{\mathrm{a}}\right)>\mathrm{G}_{22}\left(22^{\mathrm{a}}\right)>\mathrm{G}_{2}\left(11^{\mathrm{a}}\right)>\mathrm{G}_{27}\left(25^{\mathrm{a}}\right)>$ $\mathrm{G}_{26}\left(18^{\mathrm{a}}\right)>$ and $\mathrm{G}_{16}\left(10^{\mathrm{a}}\right)$ in the lower right quadrant had the highest grey leaf spot severity and are shown in decreasing order of disease severity.

Model 2 allowed detection of the variance associated with the $\mathrm{G} \times \mathrm{E}$ interaction (Fig. 4) and axis 1 and axis 2 accounted for approximately 38.3 and $23.0 \%$ of variance associated with this interaction, respectively.

The genotypes $G_{9}$ and $G_{1}$ were nearest to the vertex, which indicated that they were resistant to grey leaf spot and that this resistance was relatively insensitive to environmental effects due to minimal $\mathrm{G} \times \mathrm{E}$ interactions. However, the remaining genotypes were sensitive to environmental effects in terms of their responses to grey leaf spot and exhibited large $\mathrm{G} \times \mathrm{E}$ interactions.

Genotypes with specific adaptations to particular environments are generally chosen based on a positive relationship between that genotype's position and the respective environment in the same vectorial direction, such as for crop yield, for which a vector with a small angle (coincident straight line) indicates a positive correlation between genotype and environment. However, genotypes with specific adaptation for disease resistance can be identified by the inverse orientation of the vectors for genotype and environment. Thus, the best genotypes to select for adaptation to environmental conditions should be those with the lowest average grey leaf spot severity.

Genotypes with specific adaptations were those with a reverse vectorial orientation relative to the environment, according to the proposed model. Figures 4 and 5 show that genotypes $\mathrm{G}_{20}(0 \cdot 1 \%)$ and 

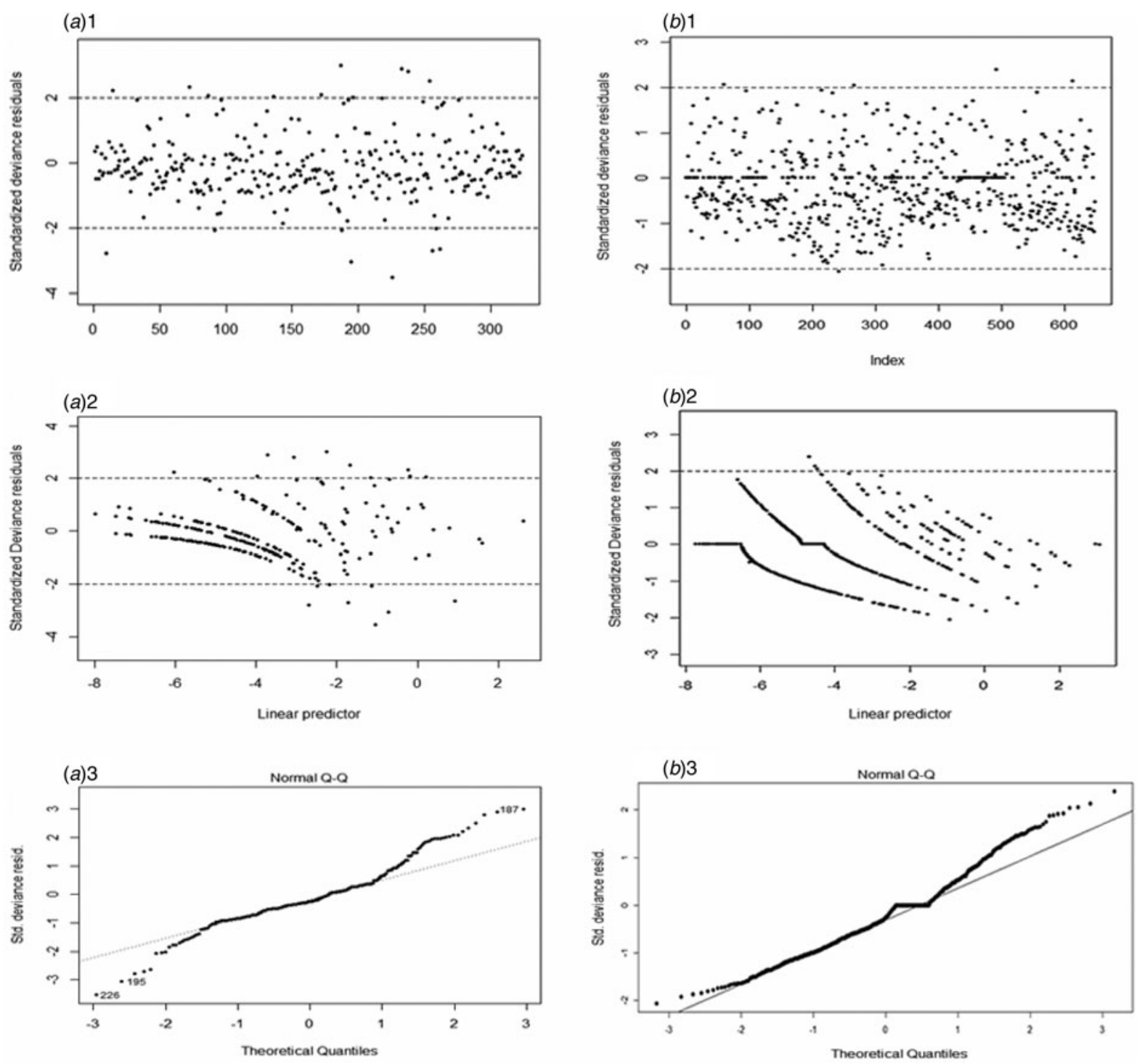

Fig. 3. Graphical diagnoses for the quasi-likelihood models: Standardized deviance residuals/linear predictor, index, and Normal QQ plots; index $(i)$, where $\mathrm{i}$ is the sequential order in which the values $y_{i}$ were measured (proportion or percentage leaf area severity affected on plot for genotypes). $\left(A_{i}\right)$ Model 1 , link function logit and variance function $V(\mu)=$ $\mu(1-\mu) ;\left(B_{i}\right)$ Model 2, logit link function and variance function $V(\mu)=[\mu(1-\mu)]^{2}$.

$\mathrm{G}_{10}(0 \cdot 0 \%)$ showed a specific adaptability to São Sebastião do Paraíso. Similarly, genotype $\mathrm{G}_{35}$ $(35.0 \%)$, which had the same vectorial direction as the environment and high average disease severity, could not be recommended for Goiania, while $\mathrm{G}_{24}$ $(0 \cdot 0 \%)$ and $\mathrm{G}_{8}(0 \cdot 0 \%)$ were adapted to Goiania.

The genotypes with higher specific adaptability for Ponta Grossa are $\mathrm{G}_{16}$ and $\mathrm{G}_{19}$, with average disease severities of $1 \%$. Genotypes $\mathrm{G}_{3}$ and $\mathrm{G}_{11}$ had lower average disease severities $(0.0 \%)$ and greater adaptability for Jataí. The most desirable genotypes for the Planaltina region were $\mathrm{G}_{12}$ and $\mathrm{G}_{4}$, due to their specific adaptability and disease severities of $0 \%$. Because of their high disease severity, genotypes $\mathrm{G}_{29}(40 \cdot 0 \%)$ and $\mathrm{G}_{28}(30 \cdot 0 \%)$ should not be recommended for use in breeding cultivars to grow in Planaltina. $\mathrm{G}_{33}(0 \cdot 5 \%)$ and $\mathrm{G}_{26}(1 \%)$ are the most appropriate genotypes to recommend for use in Patos de Mina. No genotype was particularly well adapted to the conditions of Campo Mourão. On the other hand, two genotypes could be highly recommended for use in Goianésia, $\mathrm{G}_{6}(0.5 \%)$ and $\mathrm{G}_{26}$ $(0.5 \%)$; the latter was highly adapted to that environment. 
Table 4. Analysis of deviance (ANODEV) for proportion of grey leaf spot severity, using model 2 with logit link function and variance function $\left.\operatorname{Var}(\mu)=[\mu(1-\mu)]^{2}\right]$

\begin{tabular}{lrrrrrrrrr}
\hline \hline Source of variation & D.F. & Qdev. & Qdev. mean & Quasi-residuals & $F$ & $P>F$ & D.F. Gollob & $F_{\text {Gollob }}$ & $P>F$ \\
\hline Blocks/locations & 9 & $12 \cdot 3$ & $1 \cdot 37$ & $2298 \cdot 1$ & $0 \cdot 71$ & $0 \cdot 1005$ & 9 & $1 \cdot 92$ & $0 \cdot 0483$ \\
Locations (L) & 8 & $1045 \cdot 1$ & $130 \cdot 6$ & $2310 \cdot 4$ & $68 \cdot 5$ & $<2 \cdot 2 e^{-16}$ & 8 & $95 \cdot 35$ & $0 \cdot 0 \mathrm{E}+00$ \\
Genotypes (G) & 35 & $1176 \cdot 2$ & $33 \cdot 6$ & $1121 \cdot 9$ & $17 \cdot 61$ & $<2 \cdot 22 e^{-16}$ & 35 & $47 \cdot 15$ & $0 \cdot 0 \mathrm{E}+00$ \\
Axis 1 & 42 & $429 \cdot 6$ & $10 \cdot 2$ & $692 \cdot 2$ & $5 \cdot 4$ & $<2 \cdot 22 e^{-16}$ & 42 & $12 \cdot 56$ & $0 \cdot 0 \mathrm{E}+00$ \\
Axis 2 & 40 & $258 \cdot 3$ & $6 \cdot 5$ & $433 \cdot 9$ & $3 \cdot 4$ & $<2 \cdot 22 e^{-16}$ & 40 & $10 \cdot 95$ & $0 \cdot 0 \mathrm{E}+00$ \\
Residual axis & 198 & 433.9 & $2 \cdot 19$ & & & $1 \cdot 45$ & $0 \cdot 1650$ & & \\
Error & 315 & $-224 \cdot 5$ & & & & & & & \\
Total & 647 & $3355 \cdot 5$ & & & & & & \\
\hline \hline
\end{tabular}

D.F., degrees of freedom; Qdev., quasi-deviance.

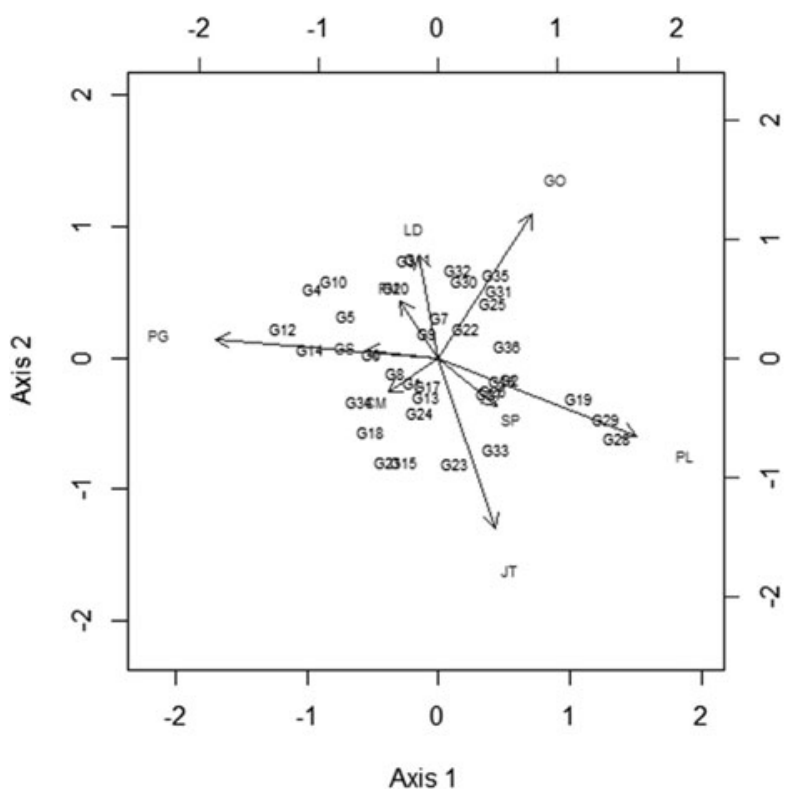

Fig. 4. The $\mathrm{G} \times \mathrm{E}$ interaction for grey leaf spot severity using the GAMMI model 2 with the link function logit and variance $V(\mu)=[\mu(1-\mu)]^{2}$. The quasi-deviance proportion of the axis 1 accounts for $38.30 \%$ of the $G \times E$ interaction and that of axis 2 accounts for $23.0 \%$ of the $G \times E$ interaction. Locations: Campo Mourão (CM), Goiânia (GO), Goianésia (GS), Jataí (JT), Londrina (LD), Ponta Grossa (PG), Planaltina (PL), Patos de Minas (PM) and São Sebastião do Paraíso (SP).

\section{DISCUSSION}

Because the current statistical approach is not routinely applied for the analysis of disease severity data in maize under field conditions, the data distribution had to first be characterized, then the model that best fitted the data had to be determined. The suitability of the present data for the proposed model can be seen in Fig. 3. Note the random distribution of

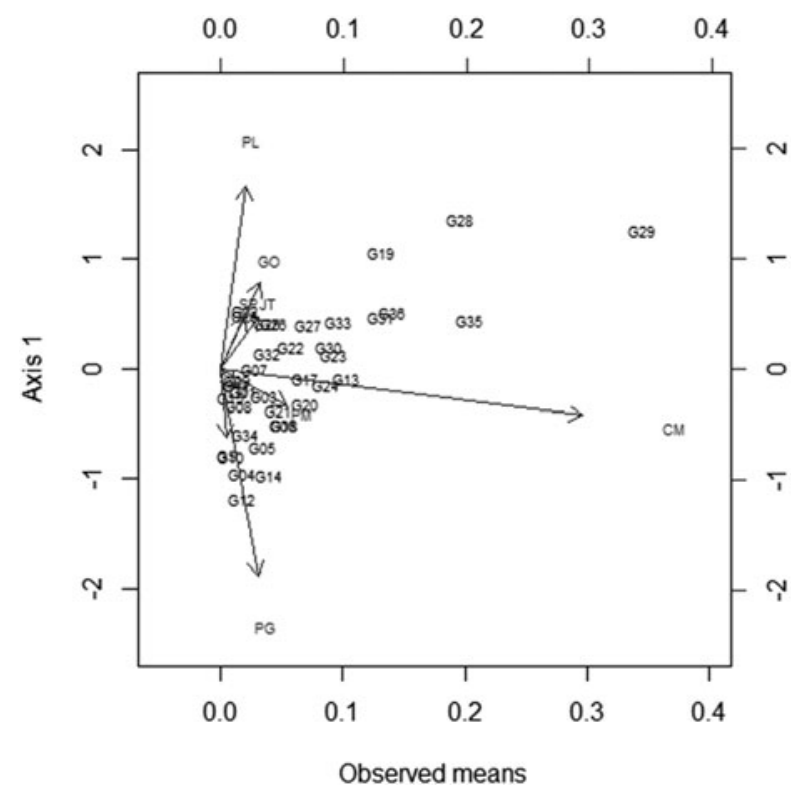

Fig. 5. GAMMI graphic that shows the relationship between the average severity of grey leaf spot and the first term of the $\mathrm{G} \times \mathrm{E}$ interaction. Locations: Campo Mourão (CM), Goiânia (GO), Goianésia (GS), Jataí (JT), Londrina (LD), Ponta Grossa (PG), Planaltina (PL), Patos de Minas (PM) and São Sebastião do Paraíso (SP).

residuals around zero, which suggests a lack of correlation between the errors; the influence of error was minor, as can be seen in the Normal QQ plot (Fig. 3); points far out of alignment were not observed. Thus, the Wedderburn model with a logistic function was appropriate to describe the data set.

The ANODEV was significant for genotype and environment as well as significant for the two first axes of the interaction (Table 4). In this decomposition, the singular value represents the level of association between these factors. Because the variable response 
was within the interval $[0,1]$ the logistic link function was used. Thus, the quasi-likelihood models were evaluated with the logit link and the variance functions $\operatorname{Var}(\mu)=\mu(1-\mu)$ and $\operatorname{Var}(\mu)=[\mu(1-\mu)]^{2}$. Therefore, the Wedderburn model, model 2, more reliably described the data (Fig. 3).

Among the adjusted models, model 2 showed fewer discrepant values, did not violate the initial assumptions, and presented significant coefficients, so it was the most suitable model to describe the responses in these data. The cumulative proportion of quasi-deviance of the two first axes relative to the total quasideviance was high (61.3\%) (Table 5). However, at least $75 \%$ of the total variance could be attributed to the first two PC axes (Ferreira 2008). This indicates that these components could replace the $n$ original variables without excessive loss of information. These axes measured methodological efficiency, but they could also be used to quantify the $G \times E$ interaction.

Although the basic assumptions necessary to estimate the stability and adaptability of genotypes in various environments are usually violated, the GAMMI methodology is a step forward in detecting interaction effects. Previously, the required computational methods hindered application of the GAMMI method, but specific routines are now available in $\mathrm{R}$ (these commands are shown Appendix A) to fit these multiplicative interaction models using van Eeuwijk's algorithm (1995). The SVD of the residual matrix used to obtain the coefficients for the main effects is shown in Table 6 together with the environment and genotype scores.

Duarte \& Vencovsky (1999) stated that favourable combinations of genotypes and environments have coordinates with the same sign and are graphically distant from the vertex. The positive or negative interactions depicted by the biplot, principally those of high magnitude, can be useful in plant breeding programmes. For disease severity, combinations with opposite signs were of interest because they indicated genotypes suited to particular environments. Graphical representation as a biplot also permits the quick identification of more productive environments with scores of approximately zero that contribute less to the $\mathrm{G} \times \mathrm{E}$ interaction. Such environments could also be favourable locations for the preliminary steps of a plant breeding programme (Pacheco et al. 2003). Therefore, genotypes and environments with low scores for the interaction axes contribute less to model variance and are considered stable. These genotypes could be recommended for growing on large
Table 5. Quasi-deviance proportion in relation to the proposed axes for the mean values of grey leaf spot severity

\begin{tabular}{llll}
\hline \hline Axes & Quasi-deviance & $\begin{array}{l}\text { Quasi-deviance } \\
\text { proportion }\end{array}$ & $\begin{array}{l}\text { Cumulative } \\
\text { proportion }\end{array}$ \\
\hline Axis 1 & $429 \cdot 6$ & 0.383 & $0 \cdot 383$ \\
Axis 2 & $258 \cdot 3$ & $0 \cdot 230$ & 0.613 \\
Residuals & 433.9 & 0.387 & $1 \cdot 000$ \\
\hline \hline
\end{tabular}

crop acreage due to their high mean crop yields and disease resistance.

In the analyses of the stability and adaptability of genotypes using multiplicative models, the interaction effects can be evaluated using graphical representations that approximate the SVD residual matrix of the model with another low rank matrix. The biplot facilitates identification and understanding of the components of the G $\times$ E interaction. Rencher (2002) defined the biplot as a two-dimensional representation of the data matrix that defines the SVD produced by the SVD method. Here, the data matrix is the $R_{\text {(gxe), }}$ which identifies an element for every $g$ vector of observations ( $g$ lines in the $R_{\text {(gxe) }}$ matrix, or genotypes) simultaneously with an element for every e variable (e columns in the $R_{\text {(gxe) }}$ matrix, or locations). Therefore, with this technique, one can readily identify productive genotypes with wide adaptability for megaenvironments, limit genotypes with specific adaptability to determined agronomic zones, and identify the environments that should be tested (Kempton 1984; Gauch \& Zobel 1996; Ferreira et al. 2006).

The graphic interpretation in Fig. 5 depicts the variation caused by the main additive effects of genotype and environment and the multiplicative effect of the G $\times$ E interaction (Gauch \& Zobel 1996; Smith et al. 2005). The abscissa represents the main effects (i.e., the overall averages of the variables for the genotypes evaluated) and the ordinate is the first interaction axis (axis 1). In this case, the lower the absolute value of axis 1 , the lower its contribution to the $\mathrm{G} \times \mathrm{E}$ interaction; therefore, the more stable the genotype. The ideal genotype is one with high productivity and an axis 1 value near zero. An undesirable genotype has low stability associated with low productivity (Kempton 1984; Gauch \& Zobel 1996; Ferreira et al. 2006).

In the biplot analysis shown in Fig. 4, the cosine of the angle between a vector and an axis indicates the contribution of that variable to the axis dimension. Also, the cosine of the angle between the vectors for 
Table 6. GAMMI coefficients for main effects and the scores from environments and genotypes

\begin{tabular}{|c|c|c|c|}
\hline $\begin{array}{l}\text { Locations and } \\
\text { genotypes }\end{array}$ & $\begin{array}{l}\text { Estimates of } \\
\text { coefficients }\end{array}$ & Axis 1 & Axis 2 \\
\hline Intercept & $-1 \cdot 642$ & - & - \\
\hline $\mathrm{CM}$ & - & $0 \cdot 138$ & $-0 \cdot 135$ \\
\hline GO & $-5 \cdot 840$ & $2 \cdot 270$ & $2 \cdot 171$ \\
\hline GS & $-5 \cdot 377$ & $-1 \cdot 064$ & $0 \cdot 383$ \\
\hline JT & $-4 \cdot 224$ & $1 \cdot 278$ & $-0 \cdot 458$ \\
\hline LD & $-4 \cdot 983$ & $0 \cdot 856$ & 0.971 \\
\hline PG & $-2 \cdot 934$ & $-1 \cdot 054$ & 0.053 \\
\hline PL & $-6 \cdot 075$ & $1 \cdot 022$ & $-2 \cdot 323$ \\
\hline PM & $-2 \cdot 478$ & $0 \cdot 112$ & 0.099 \\
\hline $\mathrm{SP}$ & $-5 \cdot 039$ & $1 \cdot 610$ & $-1 \cdot 198$ \\
\hline CM:rep2 & $-0 \cdot 109$ & - & - \\
\hline GO:rep2 & $0 \cdot 648$ & - & - \\
\hline GS:rep2 & 0.696 & - & - \\
\hline JT:rep2 & $0 \cdot 164$ & - & - \\
\hline LD:rep2 & 0.928 & - & - \\
\hline PG:rep2 & $-0 \cdot 102$ & - & - \\
\hline PL:rep2 & $-0 \cdot 167$ & - & - \\
\hline PM:rep2 & $-0 \cdot 353$ & - & - \\
\hline SP:rep2 & $0 \cdot 248$ & - & - \\
\hline $\mathrm{G}_{1}$ & - & $-0 \cdot 423$ & $-0 \cdot 570$ \\
\hline $\mathrm{G}_{2}$ & $-0 \cdot 084$ & $0 \cdot 229$ & $-0 \cdot 813$ \\
\hline $\mathrm{G}_{3}$ & $0 \cdot 530$ & -0.437 & $0 \cdot 892$ \\
\hline $\mathrm{G}_{4}$ & $0 \cdot 020$ & $-1 \cdot 103$ & 0.356 \\
\hline $\mathrm{G}_{5}$ & $0 \cdot 442$ & $-1 \cdot 506$ & $0 \cdot 272$ \\
\hline $\mathrm{G}_{6}$ & $0 \cdot 789$ & -0.758 & -0.535 \\
\hline $\mathrm{G}_{7}$ & $0 \cdot 849$ & $0 \cdot 326$ & $0 \cdot 276$ \\
\hline $\mathrm{G}_{8}$ & $0 \cdot 640$ & $-0 \cdot 710$ & $0 \cdot 499$ \\
\hline $\mathrm{G}_{9}$ & $-0 \cdot 318$ & $0 \cdot 143$ & $-0 \cdot 258$ \\
\hline $\mathrm{G}_{10}$ & $0 \cdot 049$ & $-1 \cdot 158$ & $0 \cdot 381$ \\
\hline $\mathrm{G}_{11}$ & $-0 \cdot 113$ & $-0 \cdot 237$ & 0.798 \\
\hline $\mathrm{G}_{12}$ & $-0 \cdot 288$ & $-1 \cdot 175$ & $0 \cdot 162$ \\
\hline $\mathrm{G}_{13}$ & $2 \cdot 402$ & $-0 \cdot 180$ & $-0 \cdot 248$ \\
\hline $\mathrm{G}_{14}$ & $-0 \cdot 103$ & $-1 \cdot 210$ & $0 \cdot 155$ \\
\hline $\mathrm{G}_{15}$ & $-0 \cdot 203$ & -0.619 & -0.091 \\
\hline $\mathrm{G}_{16}$ & $0 \cdot 258$ & $-0 \cdot 009$ & $-1 \cdot 060$ \\
\hline $\mathrm{G}_{17}$ & $0 \cdot 571$ & $-0 \cdot 077$ & 0.559 \\
\hline $\mathrm{G}_{18}$ & $1 \cdot 139$ & $-0 \cdot 684$ & $-0 \cdot 817$ \\
\hline $\mathrm{G}_{19}$ & $2 \cdot 771$ & $-0 \cdot 751$ & $-1 \cdot 411$ \\
\hline $\mathrm{G}_{20}$ & $1 \cdot 259$ & $-0 \cdot 564$ & 0.980 \\
\hline $\mathrm{G}_{21}$ & 0.972 & -0.630 & $-0 \cdot 707$ \\
\hline $\mathrm{G}_{22}$ & 0.907 & $1 \cdot 524$ & 0.095 \\
\hline $\mathrm{G}_{23}$ & $1 \cdot 808$ & $-0 \cdot 286$ & $-0 \cdot 803$ \\
\hline $\mathrm{G}_{24}$ & $1 \cdot 640$ & -0.732 & $-0 \cdot 814$ \\
\hline $\mathrm{G}_{25}$ & $0 \cdot 251$ & $1 \cdot 040$ & 0.628 \\
\hline $\mathrm{G}_{26}$ & 0.913 & $0 \cdot 473$ & $-0 \cdot 193$ \\
\hline $\mathrm{G}_{27}$ & $1 \cdot 538$ & $0 \cdot 110$ & $-0 \cdot 366$ \\
\hline $\mathrm{G}_{28}$ & $2 \cdot 938$ & $1 \cdot 234$ & $-0 \cdot 830$ \\
\hline $\mathrm{G}_{29}$ & $3 \cdot 840$ & $1 \cdot 476$ & $-0 \cdot 546$ \\
\hline $\mathrm{G}_{30}$ & $1 \cdot 723$ & $0 \cdot 175$ & $1 \cdot 055$ \\
\hline
\end{tabular}

Table 6. (Cont.)

\begin{tabular}{lcrr}
\hline \hline $\begin{array}{l}\text { Locations and } \\
\text { genotypes }\end{array}$ & $\begin{array}{l}\text { Estimates of } \\
\text { coefficients }\end{array}$ & Axis 1 & Axis 2 \\
\hline $\mathrm{G}_{31}$ & $2 \cdot 501$ & 0.973 & $0 \cdot 322$ \\
$\mathrm{G}_{32}$ & $1 \cdot 413$ & $0 \cdot 355$ & $0 \cdot 817$ \\
$\mathrm{G}_{33}$ & $1 \cdot 125$ & 1.599 & $-0 \cdot 198$ \\
$\mathrm{G}_{34}$ & 0.652 & $-1 \cdot 029$ & 0.254 \\
$\mathrm{G}_{35}$ & 2.963 & $1 \cdot 043$ & 0.445 \\
$\mathrm{G}_{36}$ & $2 \cdot 566$ & 0.926 & 0.635 \\
\hline \hline
\end{tabular}

CM, Campo Mourão; GO, Goiânia; GS, Goianésia; JT, Jataí; LD, Londrina; PG, Ponta Grossa; PL, Planaltina; PM, Patos de Minas; SP, São Sebastião do Paraíso; Rep2, Repetition 2.

two environments approximates their correlation. Therefore, when vectors are perpendicular, the cosine of the angles between them equals zero and the variables are independent. But if the vectors for two variables are at very close angles or at a $180^{\circ}$ angle, they are highly positively or negatively correlated (Gower 1995; Kroonenberg 1997). The angles between the vectors for sites and genotypes, and the positions of the vectors, permitted us to identify genotypes positively or negatively correlated with particular environments (Table 7).

The negative correlation between cultivar and location has helped to identify genotypes with specific adaptations. Genotypes with a highly negative correlation within an environment had the lowest disease severities (Fig. 4 and Fig. 5), and should therefore be recommended for use in those locations.

\section{CONCLUSIONS}

The GAMMI method efficiently described the data regarding stability and adaptability of genotypes to grey leaf spot incidence in various locations in Brazil using available theories and the computational resources outlined in the present paper. A pattern of differential responses to grey leaf spot in different environments was found, and the GAMMI method could explain $61 \cdot 3 \%$ of the variance due to the $\mathrm{G} \times \mathrm{E}$ interaction with only two PC. The two-dimensional analysis detected the presence of a strong interaction between genotype and environment.

The GAMMI model could efficiently identify and quantify the $\mathrm{G} \times \mathrm{E}$ interactions, even though the data were not normally distributed and variances were heterocedastic. The present analyses indicated that the genotypes $G_{9}$ and $G_{1}$ could be recommended because of their high stability and low severity of 
Table 7. Genotypes positively or negatively associated with specific environments

\begin{tabular}{lll}
\hline \hline Locations & $\begin{array}{l}\text { High positive } \\
\text { correlation Genotypes } \\
\text { unfavourable }\end{array}$ & $\begin{array}{l}\text { High negative } \\
\text { correlation Genotypes } \\
\text { favourable }\end{array}$ \\
\hline GS & $\mathrm{G}_{6}$ & $\mathrm{G}_{26}$ \\
PM & - & $\mathrm{G}_{22}$ \\
SP & $\mathrm{G}_{26}$ & $\mathrm{G}_{6}$ and $\mathrm{G}_{10}$ \\
PG & $\mathrm{G}_{14}$ & $\mathrm{G}_{16}$ and $\mathrm{G}_{19}$ \\
$\mathrm{GO}$ & $\mathrm{G}_{35}$ & $\mathrm{G}_{24}$ and $\mathrm{G} 8$ \\
$\mathrm{JT}$ & $\mathrm{G}_{22}, \mathrm{G}_{23}$ and $\mathrm{G}_{33}$ & $\mathrm{G}_{3}$ and $\mathrm{G}_{11}$ \\
PL & $\mathrm{G}_{2}, \mathrm{G}_{29}$ and $\mathrm{G}_{28}$ & $\mathrm{G}_{12}$ and $\mathrm{G}_{4}$ \\
\hline
\end{tabular}

GS, Goianésia; PM, Patos de Minas; SP, São Sebastião do Paraíso; PG, Ponta Grossa; GO, Goiânia; JT, Jataí; LD, Londrina; PL, Planaltina.

grey leaf spot. Campo Mourão, Goianésia, Londrina, and São Sebastião do Paraíso were locations in which average disease severity was more stable, indicating that these locations made a minor contribution to the $\mathrm{G} \times \mathrm{E}$ interaction. The scores from these environments had values close to the vertex in the figures, which indicated less variability among genotypes for disease severity. However, the responses to disease in these locations were distinct. For example, Campo Mourão exhibited low variability and high severity of grey leaf spot (36.8\%). Genotypes with specific adaptability and low severity of grey leaf spot for specific locations were $G_{26}$ for Goianésia, $G_{24}$ and $G_{8}$ for Goiânia, $G_{3}$ and $G_{11}$ for Jataí, $\mathrm{G}_{19}$ and $\mathrm{G}_{16}$ for Ponta Grossa, $\mathrm{G}_{12}$ and $\mathrm{G}_{4}$ for Planaltina, $\mathrm{G}_{26}$ and $\mathrm{G}_{33}$ for Patos de Minas, and $\mathrm{G}_{10}$ and $\mathrm{G}_{20}$ for São Sebastião do Paraíso. These results will be useful to guide recommendations of cultivars with stable resistance to grey leaf spot and high yield in particular environments.

\section{REFERENCES}

Agresti, A. (2002). Categorical Data Analysis. New Jersey, USA: John Wiley \& Sons.

Allard, R.W. (1999). Principles of Plant Breeding. New York, USA: John Wiley \& Sons.

AnNicCHiarico, P., Bellah, F. \& Chiarl, T. (2005). Defining subregions and estimating benefits for a specific-adaptation strategy by breeding programs: a case study. Crop Science 45, 1741-1749.

Bhatia, A. \& MunkVold, G. P. (2002). Relationships of environmental and cultural factors with severity of gray leaf spot in maize. Plant Disease 86, 1127-1133.

Brito, A. H., Von Pinho, R. G., Pozza, E. A., Pereira, J. L. A. R. \& Faria Filho, E. M. (2007). Efeito da Cercosporiose no rendimento de híbridos comerciais de milho Fitopatologia Brasileira 32, 472-479.

Cordeiro, G.M. \& Demétrio, C. G. B. (2008). Modelos Lineares Generalizados e Extensões. Piracicaba, Brazil: Escola Superior de Agricultura "Luiz de Queiroz" Universidade de São Paulo.

Crossa, J., Fox, P. N., Pfeiffer, W. H., Rajaram, S. \& Gauch, H. G., Jr (1991). AMMI adjustment for statistical analysis of an international wheat yield trial. Theoretical and Applied Genetics 81, 27-37.

Cruz, C. D., Regazzl, A.J. \& Carneiro, P. C.S. (2006). Modelos Biométricos Aplicados ao Melhoramento Genético. Viçosa, Brazil: Universidade Federal de Viçosa.

Dobson, A. J. A. (2002). Introduction to Generalized Linear Models. New York, USA: Chapman \& Hall CRC.

DUARTE, J. B. \& VenCovskY, R. (1999). Interação Genótipos X Ambientes uma introdução à análize "AMMI". Monograph Series, 9. Ribeirão Preto, Brazil: Sociedade Brasileira de Genética.

Fantin, G. M., Brunelli, K. R., Resende, I. C. \& Duarte, A.P. (2001). A mancha de Cercospora do milho. Campinas, Brazil: Instituto Agronômico de Campinas.

ForNASIERI Filho, D. (2007). Manual da Cultura do Milho. Jaboticabal, Brazil: Funep.

FerReIRA, D. F. (2008). Estatística Multivariada. Lavras, Brazil: Universidade Federal de Lavras.

Ferreira, D. F., Demétrio, C. G. B., Manly, B. F. J., Machado, A. A., VENCOVSKY, R. (2006). Statistical models in agriculture: biometrical methods for evaluating phenotypic stability in plant breeding. Cerne 12, 373-388.

GABRIEL, R. (1998). Generalized bilinear regression. Biometrika 85, 689-700.

Gauch, H. G. \& Zobel, R. W. (1988). Predictive and postdictive success of statistical analyses of yield trials. Theoretical and Applied Genetics 76, 1-10.

Gauch, H. G. \& Zobel, R. W. (1996). AMMI analysis of yield trials. In Genotype by Environment Interaction (Eds M. S. Kang \& H. G. Gauch), pp. 85-122. New York, USA: Boca Raton CRC Press.

Gollob, H. F. (1968). A statistical model which combines features of factor analytic and analysis of variance techniques. Psychometrika 33, 73-115.

GoWER, J. C. (1995). A general theory of biplots. In Recent Advances in Descriptive Multivariate Analysis (Ed. W. J. Krzanowski), pp. 283-303. Royal Statistical Society Lecture Notes, 2. Oxford: Clarendon Press.

Hadi, A. F., Mattjik, A. A. \& Sumertajaya, I. M. (2010). Generalized AMMI models for assessing the endurance of soybean to leaf pest. Jurnal IImu Dasar 11, 151-159.

IENTILUCCI, E.J. (2003). Using the Singular Value Decomposition. New York, USA: Chester F. Carlson Center for Imaging Science, Rochester Institute of Technology. Available from: http://www.cis.rit.edu/ $\sim$ ejipci/Reports/svd.pdf (verified 27 October 2016).

KeMPTON, R. A. (1984). The use of biplots in interpreting variety by environment interactions. Journal of Agricultural Science, Cambridge 103, 123-135.

KroOnenBerG, P. M. (1997). Introduction to Biplots for $G \times E$ Tables. Research Report \#51. Leiden: Leiden University. 
McCullagh, P. \& Nelder, J.A. (1989). Generalized Linear Models. London, UK: Chapman \& Hall.

Pacheco, R. M., Duarte, J. B., Assunção, M. S., Junior, J. N. \& Chaves, A. A. P. (2003). Zoneamento e adaptação produtiva de genótipos de soja de ciclo médio de maturação para Goiás. Pesquisa Agropecuária Tropical 33, 23-27.

Paula, G. A. (2004). Modelos de Regressão com Apoio Computacional. São Paulo, Brazil: Instituto de Matemática e Estatística da Universidade de São Paulo (IME-USP)..

R Development Core Team (2013). R: A Language and Environment for Statistical Computing. Vienna, Austria: R Foundation for Statistical Computing. Available from: http://www.R-project.org/

RenCher, A. C. (2002). Methods of Multivariate Analysis, 2nd edn. New York, USA: John Wiley \& Sons.

Searle, S. R., Casella, G. \& McCulloch, C. E. (1992). Variance Components. New York, USA: John Wiley \& Sons.

Smith, A. B., Cullis, B. R. \& Thompson, R. (2005). The analysis of crop cultivar breeding and evaluation trials: an

\section{APPENDIX A}

The multiplicative term of this model was estimated in R software with the generalized nonlinear models gnm function using the Mult (factor ${ }_{1}$, factor $_{2}$, inst $=$ ...) command, which specifies the multiplicative interactions that are linear or nonlinear predictors. The subscripts 1 and 2 represent the multiplicative factors of the interaction and inst is an integer that specifies the number of interactions (Turner \& Firth overview of current mixed model approaches. Journal of Agricultural Science, Cambridge 143, 449-462.

SumerTAjAYA, I. M. (2007). Analisis Statistik Interaksi Genotipe Dengan Lingkungan. Bogor, Indonesia: Departemen Statistik, Fakultas Matematika dan IPA, IPB (Abstract in English).

TARAKANOVAS, P. \& RUZGAS, V. (2006). Additive main effect and multiplicative interaction analysis of grain yield of wheat varieties in Lithuania. Agronomy Research 4, 91-98.

TURNeR, H. \& FIRTH, D. (2009). Generalized Nonlinear Models in R: An Overview of the gnm Package ( $R$ Package Version 0.10-0). Warwick, UK: University of Warwick.

van EeumiJK, F. A. (1995). Multiplicative interaction in generalized linear models. Biometrics 51, 1017-1032.

WeDDERBURN, R. W.M. (1974). Quasi-likelihood functions, generalized linear models and the Gauss-Newton method. Biometrika 61, 439-447.

Zobel, R. W., Wright, M. J. \& Gauch, H. G. (1988). Statistical analysis of a yield trial. Agronomy Journal 80, 388-393.

2009). The function residSVD (model, fac 1 , and fac2,$d=\ldots$ ) performed the SVD of the residual matrix. This residSVD function uses the first $d$ components of the SVD to approximate a residual vector from the model by adding $d$ multiplicative terms (Turner \& Firth 2009). Finally, the model is re-adjusted by the update command (object, formula ... evaluate $=T R U E)$, which assumes the coefficients from the previous model as starting values for the new model. 